\title{
Distribution of Endotracheally Instilled Surfactant Protein SP-C in Lung-Lavaged Rabbits
}

\author{
S. BAMBANG OETOMO, L. DE LEY, T. CURSTEDT, J. G. TER HAAR, C. SCHOOTS,
} CH. R. H. WILDEVUUR, AND A. OKKEN

\author{
Department of Pediatrics, Division of Neonatology [S.B.O., A.O.], Department of Clinical Immunology [L.d.L., \\ J.G.t.H.], Department of Pathology [C.S.], and Department of Thoracic Surgery, Division of Research, State \\ University Groningen, Groningen, The Netherlands [Ch.R.H.W.]; and Department of Clinical Chemistry \\ Karolinska Hospital, Stockholm, Sweden
}

\begin{abstract}
In lung-lavaged surfactant-deficient rabbits $(n=6)$ requiring artificial ventilation, porcine surfactant was instilled endotracheally. This resulted in improvement of lung function so that the animals could be weaned off artificial ventilation. The animals were killed $4 \frac{1}{2} \mathrm{~h}$ after surfactant administration and the porcine surfactant protein was localized in the lung with a MAb. We found surfactant protein in all lobes of the lung but the distribution was not homogeneous. Surfactant protein $\mathrm{C}$ was found in less than $15 \%$ of the alveolar spaces and in less than $1 \%$ of the bronchi. (Pediatr Res 29: 178-181, 1991
\end{abstract}

\section{Abbreviations}

PEEP, positive end-expiratory pressure SP-B, surfactant protein B SP-C, surfactant protein $\mathrm{C}$

The endotracheal instillation of surfactant improves lung function in premature newborn babies with surfactant deficiency. However, the immediate beneficial effects of surfactant therapy are sometimes followed by a relapse several hours later. Factors respc isible for the relapse include patency of the ductus arteriosur (1) and inhibition of surfactant activity by proteins leaking into the alveolar space (2). Another factor that may be important is the distribution in the lung of the administered surfactant. The distribution of instilled surfactant has been subsequently measured by analysis of different components of instilled surfactant in alveolar wash and in lung tissue (3-7). However, the localization and distribution of the instilled surfactant at the microscopic level in lung tissue has not been reported. In our study, an immunohistochemical technique was used to localize the surfactant-associated protein, SP-C, with the aid of a MAb, after a clinical response.

\section{MATERIALS AND METHODS}

Animals. the experiments were performed under approved institutional animal care protocols with concern for animal welfare.

Healthy 3 -mo-old rabbits $(n=12)$ with a body weight of 2.73

Received February 12, 1990; accepted October 9, 1990.

Correspondence: S. Bambang Oetomo, M.D., Department of Pediatrics, Division of Neonatology, University Hospital, Oostersingel 59, 9713 EZ Groningen, The Netherlands.

Supported by a grant from the Swedish Heart-Lung Foundation and General Maternity Hospital Foundation (T.C.). $\pm 0.11 \mathrm{~kg}$ (mean $\pm \mathrm{SD}$ ) were treated as we described before (8). In short: after anesthesia (sodium pentobarbital $30 \mathrm{mg} / \mathrm{kg}$ body weight i.v.), the animals were put into the supine position on a heated mattress. the left carotid artery and right jugular vein were cannulated. Subsequently, the animals were intubated by means of a tracheostomy. The rabbits were then paralyzed (pancuronium bromide $0.1 \mathrm{mg} / \mathrm{kg}$ body weight) and artificially ventilated (fraction of inspired oxygen 1.0) using an Amsterdam infant ventilator MK III (Hoek Loos Co., Schiedam, The Netherlands) set in the volume-controlled mode. Tidal volume was set to $8 \mathrm{~mL} / \mathrm{kg}$ body weight at a rate of $60 \mathrm{breaths} / \mathrm{min}$. Severe respiratory failure was induced by lung lavage as follows: $\mathrm{NaCl}$ $0.9 \%\left(35 \mathrm{~mL} / \mathrm{kg}\right.$ body weight, at a temperature of $\left.38^{\circ} \mathrm{C}\right)$ was injected slowly endotracheally and gently withdrawn and this lavage was repeated four times with an interval of $5 \mathrm{~min}$. The total lavage procedure took $25 \mathrm{~min}$. While the lung lavage procedure was being performed, tidal volume was increased from 8 to $10 \mathrm{~mL} / \mathrm{kg}$ body weight with a concomitant stepwise increase in PEEP from 0 at the start to $10 \mathrm{~cm} \mathrm{H}_{2} \mathrm{O}$ at the end of the last lung lavage. Thirty min after the lung lavage, the PEEP was decreased to $5 \mathrm{~cm} \mathrm{H}_{2} \mathrm{O}$. Surfactant was administered endotracheally in six rabbits $45 \mathrm{~min}$ after the lung lavage procedure. We used Curosurf (Chiesi Co., Parma, Italy), a phospholipid fraction isolated from pig lungs (9). This phospholipid fraction, which also contained $1-2 \%$ of the hydrophobic surfactant-associated proteins, SP-B and SP-C, was suspended in saline and given at a dose of $100 \mathrm{mg}$ phospholipids/ $\mathrm{kg}$ body weight. The phospholipid concentration of Curosurf is $80 \mathrm{mg} / \mathrm{mL}$. During the instillation procedure, the position of the animals was changed according to Adams et al. (10) so that $30 \%$ of the total dose was administered to the right lower part of the lung, $30 \%$ to the left lower part, $20 \%$ to the left upper part, and $20 \%$ to the right upper part. The same procedure was followed in the six control animals except that they did not receive any surfactant or its vehicle. The total time of artificial ventilation after surfactant treatment was $4 \mathrm{~h}: 2$ $\mathrm{h}$ after surfactant instillation we started a weaning procedure in all animals; the PEEP was decreased to $2.5 \mathrm{~cm}, 1 \mathrm{~h}$ thereafter the PEEP was discontinued, and in the final hour of artificial ventilation the fraction of inspired oxygen was stepwise lowered to 0.21 . No additional pancuronium bromide was administered after this point to allow the rabbits to resume breathing spontaneously. After $30 \mathrm{~min}$ of spontaneously breathing in room air, the animals were killed with an overdose of pentobarbital.

Lung function. Blood samples for the determination of arterial $\mathrm{PO}_{2}, \mathrm{PCO}_{2}$, and $\mathrm{pH}$ were drawn from the left carotic artery. Samples were analyzed using an ABL II blood gas analyzer (Radiometer Co., Copenhagen, Denmark).

After completion of the experiments, pressure-volume characteristics of the excised lungs were obtained using the following 
procedure: The lungs were deflated in a vacuum jar and then placed in an air-tight box and the trachea was connected to a spirometer outside the box. Volume and pressure changes were recorded over a 20 -min period in which the pressure in the box was first lowered to $-30 \mathrm{~cm} \mathrm{H}_{2} \mathrm{O}$, followed by a rise to atmospheric pressure. Static compliance at $30 \mathrm{~cm} \mathrm{H}_{2} \mathrm{O}$, the stability index according to Gruenwald (11), and the expansion index according to Clements et al. (12) were determined from these measurements.

Preparation and selection of $M A b$. Immunization of BALB/c mice was performed with Curosurf by intraperitoneal injection in complete Freunds' adjuvant, followed after 1 mo by a booster given by intravascular injection. Four d later, the spleens of the animals were removed and a cell suspension prepared. The hypoxanthine phosphoribosyltransferase negative myeloma cell line X63 was used as the fusion partner, using the fusion procedure of Kennett (13) with some modifications (14). The fusion mixture was divided over four 96 -well cluster trays, which yielded 10-20 hybridomas per well. These hybridomas were recloned and the supernatants were screened for the desired properties: reaction with the porcine SP-B or SP-C and no cross-reaction with the rabbit surfactant-associated proteins.

The screening procedure was carried out directly on frozen tissue specimens from normal pigs, with rabbit lung tissue as a negative control (14). In short, tissue sections were fixed in acetone for $10 \mathrm{~min}$, air dried, and washed in PBS. Subsequently, undiluted hybridoma culture supernatant was pipetted on top of the wet sections. As a second step reagent, horseradish peroxidase-conjugated rabbit anti-mouse Ig (Dakopatts, Copenhagen, Denmark) was used, and 3-amino-9-ethyl-carbozole was the chromogen in the subsequent peroxidase reaction. A positive reaction was indicated by a reddish brown deposit. The specimens were counterstained with hematoxylin. The results were evaluated by light microscopy. Out of the 400 clones that were screened, one clone produced a supernatant that reacted with the alveolar surface of pig lung and not with rabbit lung. In the porcine lung, we found a clear brown staining of clumped material along the walls of the patent airspaces and not in the interstitium. Also, no reaction could be observed intracellularly. The supernatant containing this MAb was named PORSU- 1 and used in our study.

The reaction specificity of PORSU-1 was assessed by an ELISA (sensitivity in the ng range), using two isolated porcine surfactantassociated proteins as substrate (15). These proteins are hydrophobic and consist of an 8.7-kD polypeptide (SP-B) (16) and a 4.2-kD lipopeptide (SP-C) (17). The proteins were solubilized in methanol and put into 96-well vinyl assay plates (Costar, Badhoevedorp, The Netherlands) at a concentration of $10 \mathrm{ng}$ protein/ well. Thereafter, the methanol was evaporated under nitrogen. After blocking excess protein binding sites in the coated wells by incubation with PBS containing 5\% (vol/vol) FCS, PORSU-1 or an irrelevant $\mathrm{MAb}$ was added. Any binding of the surfactantassociated proteins with PORSU-1 or with the irrelevant MAb was visualized with a second step antibody preparation, horseradish peroxidase-conjugated rabbit anti-mouse Ig (Dakopatts) and orthophenyl diamine as a chromogen. All antibody incubations took $90 \mathrm{~min}$ and between the different steps washing was performed with PBS. A clearly positive staining was only seen when PORSU-1 was added to the plates that were coated with the 4.2-kD lipopeptide. In this way, the specificity of PORSU-1 for porcine SP-C was established. The irrelevant MAb was not reactive with the $4.2-\mathrm{kD}$ lipopeptide nor with the $8.7-\mathrm{kD}$ polypeptide.

Immunohistochemical staining of lung tissue specimens. Frozen lung tissue blocks that were stored at $-80^{\circ} \mathrm{C}$ were cut into 6$\mu \mathrm{m}$ thick sections. The area around the tissue was dried and the tissue was fixed for $10 \mathrm{~min}$ in $0.3 \% \mathrm{H}_{2} \mathrm{O}_{2}$ in methanol. Twentyfive $\mu \mathrm{L}$ of PORSU-1 was pipetted on top of the wet sections. After incubation for $30 \mathrm{~min}$ in a humidified atmosphere at room temperature, the specimens were washed three times in PBS for
$5 \mathrm{~min}$, followed by the same staining technique as was used in the selection procedure of the MAb. For light microscopic study, the sections were mounted in Kaiser glycerol gelatin (Merck, Darmstadt, West Germany).

Quantification of distribution of instilled surfactant. The lung tissue specimens were studied by light microscopy at a magnification of $100 \times$. A 42-point multipurpose counting grid (18) was placed in the ocular of the microscope. Using this grid, it was possible to score the presence of surfactant in the different structures of the microscopic specimen: each of the 42 points was identified as to structure (aerated alveoli, collapsed alveoli, bronchi, blood vessels, and cartilage) and the presence of surfactant. "Surfactant positive points" were counted for each structure in the specimens. These points were counted in patent airspaces and in collapsed areas separately.

To determine the number of readings per specimen that were required to obtain a representative score of the presence of surfactant in the lung tissue, 10 successive readings on a specimen were performed. The score of the surfactant positive points of each reading was averaged with the score of the previous reading. The average of the summated scores and the number of the readings were plotted on an average summation graph (19). After five readings, the average of the mean score was not changed by the summation of the 6 th and subsequent readings. We therefore performed five readings per lung specimen of each sample site of all animals. Consequently, 2100 points were scored for each animal.

Statistical analysis. All data are reported as mean \pm SD unless stated otherwise. Differences of means were tested by the MannWhitney U-test. A $p$ value of $\leq 0.05$ was considered to be statistically significant.

\section{RESULTS}

Blood gases. Values of arterial $\mathrm{PO}_{2}, \mathrm{PCO}_{2}$, and $\mathrm{pH}$ are shown in Figure 1. Surfactant instillation resulted in a rise in $\mathrm{PO}_{2}$ from $10.5 \pm 4.1$ to $47.2 \pm 11.3 \mathrm{kPa}(p<0.05)$ and a decrease in $\mathrm{PCO}_{2}$ from $5.5 \pm 0.5$ to $4.3 \pm 0.5 \mathrm{kPa}(p<0.05)$. In control animals, no change in arterial $\mathrm{PO}_{2}$ was observed and during the whole experiment the arterial $\mathrm{PO}_{2}$ remained significantly lower. When the PEEP was lowered, arterial $\mathrm{PCO}_{2}$ gradually increased in the control animals with a concomitant fall in $\mathrm{pH}$ and at a PEEP of $0 \mathrm{~cm} \mathrm{H}_{2} \mathrm{O}$ all animals died. The surfactant-treated animals reestablished spontaneous breathing, and in room air they maintained normal blood gases $\left(\mathrm{PO}_{2} 6.7 \pm 2.2, \mathrm{PCO}_{2} 5.4 \pm 1.0 \mathrm{kPa}\right.$, and $\mathrm{pH} 7.39 \pm 0.04)$.

Pressure-volume characteristics of lung. In Table 1, the static lung compliance, lung stability according to Gruenwald (11), and expansion index according to Clements et al. (12) are presented.

Quantification of distribution of instilled surfactant. SP-C was visible in the lung sections of all surfactant-treated animals and not in the controls. It was found focally in aerated lung parts filling up the entire alveolar space or as a condensed layer along alveolar walls, but predominantly in collapsed alveolar spaces. SP-C was found in less than $15 \%$ of the alveoli and less than $1 \%$ of the bronchi. There were large variations in the presence and distribution pattern of SP-C between the treated rabbits. The amount of SP-C in the different parts of the lung is presented in Figure 2.

\section{DISCUSSION}

The aim of the study was to determine the distribution of endotracheally instilled surfactant in lung-lavaged rabbits. We hypothesized that a natural component of surfactant would be the best indicator for the localization of surfactant. We therefore chose the small hydrophobic polypeptide to use as a "surfactant marker." Although we have no definite proof, we assume that this surfactant polypeptide is not separated easily from the phos- 

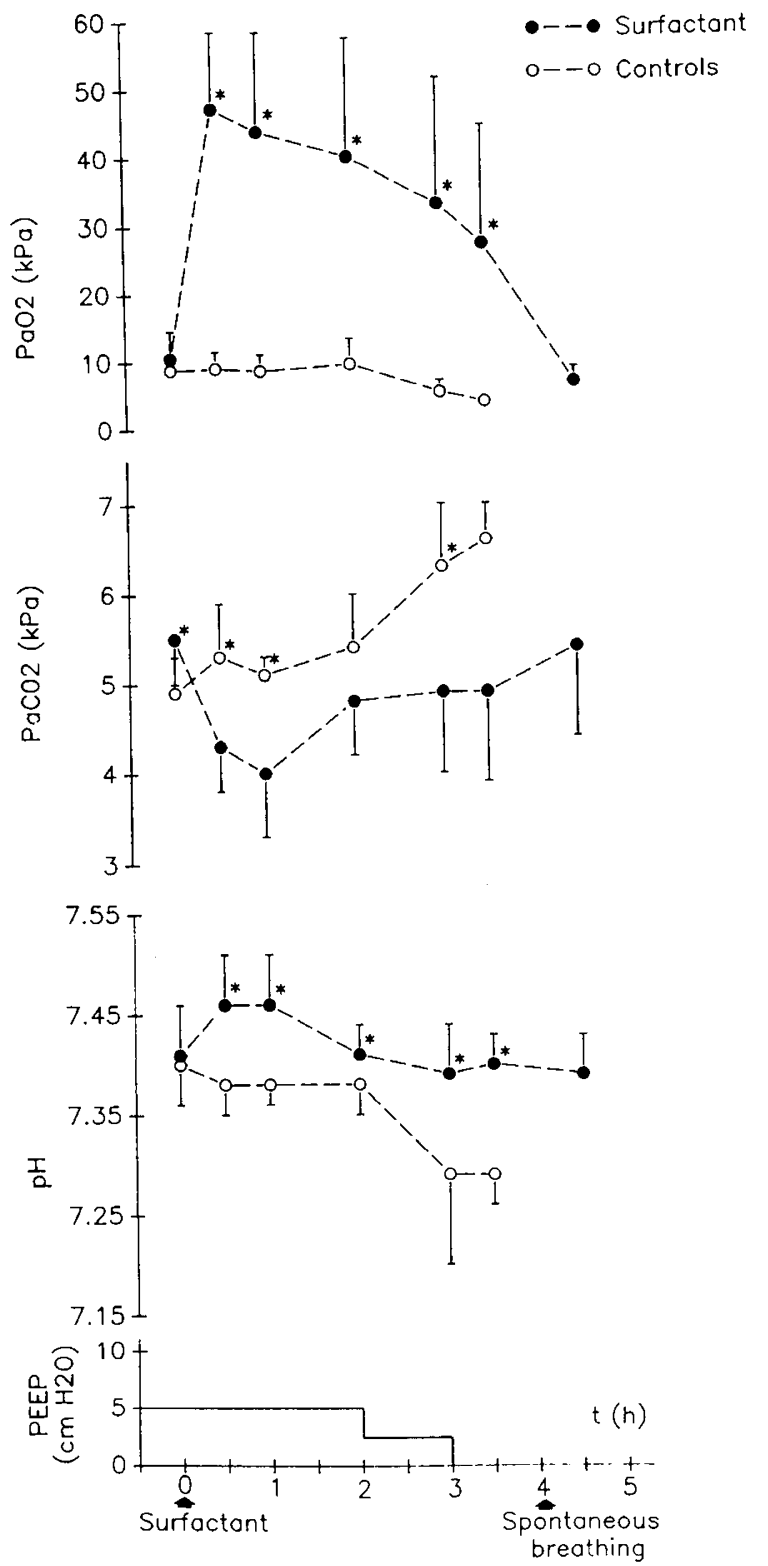

Fig. 1. Arterial $\mathrm{PO}_{2}, \mathrm{PCO}_{2}$, and $\mathrm{pH}$ of lung-lavaged rabbits before and after the endotracheal administration of porcine surfactant. Symbols for the surfactant-treated and control animals are given in the figure. The gradual decrease of PEEP is given in the lower panel.

Table 1. Static lung compliance in vitro, stability index according to Gruenwald (11), and expansion index according to Clements et al. (12) (mean $\pm S D$ ) of lung-lavaged rabbits of

which six had been treated with porcine surfactant and six served as controls

\begin{tabular}{lccc}
\hline Group & $\begin{array}{c}\text { Static compliance } \\
\left(\mathrm{mL} / \mathrm{cm} \mathrm{H}_{2} \mathrm{O} / \mathrm{kg}\right. \\
\text { body wt })\end{array}$ & $\begin{array}{c}\text { Stability } \\
\text { index } \\
(\mathrm{mL} / \mathrm{mL})\end{array}$ & $\begin{array}{c}\text { Expansion } \\
\text { index } \\
(\%)\end{array}$ \\
\hline $\begin{array}{l}\text { Surfactant-treated } \\
\text { rabbits }(n=6)\end{array}$ & $0.66 \pm 0.10$ & $1.08 \pm 0.15$ & $66 \pm 11$ \\
Controls $(n=6)$ & $0.34 \pm 0.17$ & $0.77 \pm 0.10$ & $41 \pm 3$ \\
$p$ value & 0.05 & $<0.05$ & $<0.05$ \\
\hline
\end{tabular}

pholipid fraction because it has a high affinity for the phospholipids (20) and special techniques are required to separate it from the surfactant lipids (15).

Other investigators have raised polyclonal antisera to detect surfactant apoprotein in lung tissue and isolated type II cells (2123). In this study, we prepared a MAb that reacted specifically

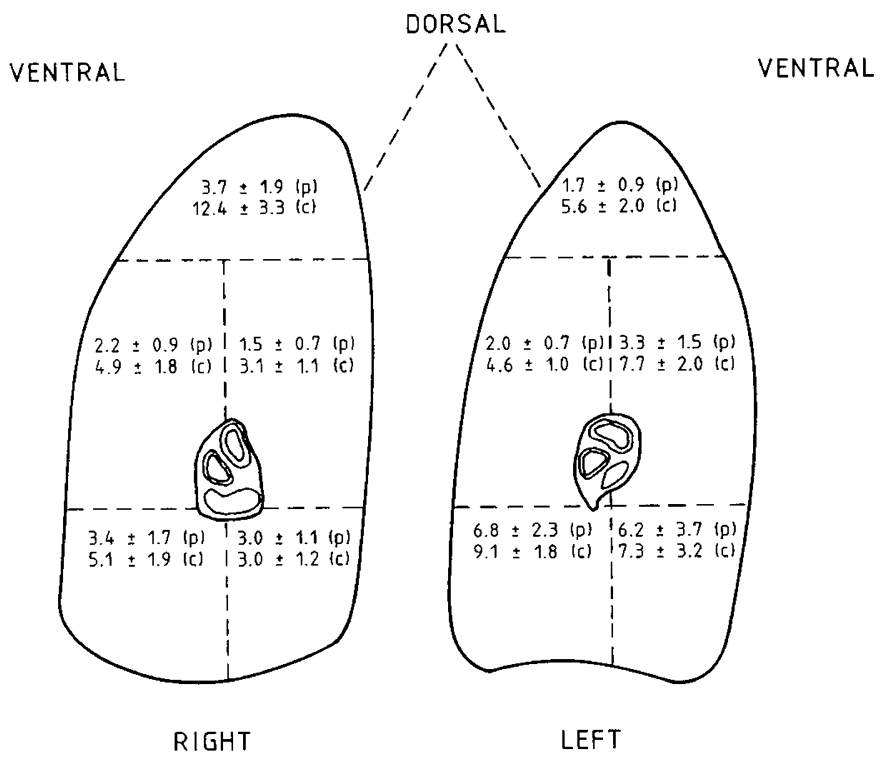

Fig. 2. Relative distribution of porcine SP-C over patent $(p)$ and collapsed $(c)$ areas in the different lung parts, expressed as number of surfactant positive points (mean $\pm \mathrm{SEM}$ ), in lung-lavaged rabbits that were treated with porcine surfactant endotracheally.

with the 4.2-kD surfactant lipopeptide (SP-C) of the porcine surfactant preparation but not with the endogenous rabbit surfactant. We showed that surfactant treatment of the lung-lavaged rabbits was effective in improving lung function. We therefore assumed that if SP-C remained closely associated with the instilled surfactant phospholipids we would find a uniform distribution of SP-C along the alveolar lining of most of the lung. However, the results of the immunohistochemical staining of the lung tissue clearly demonstrated that this was not the case. We found a large variation in the presence and distribution of the SP-C between the surfactant-treated rabbits. Surprisingly, SP-C was localized in less than $15 \%$ of the alveolar spaces, yet it was possible to wean the rabbits off the artificial ventilation, with subsequent spontaneous breathing in room air. Inhomogenous distribution of substituted surfactant phospholipids has been experimentally shown before $(6,24)$. Recently, we and others have shown in rabbits that the distribution is dependent on the volume of the instilled surfactant $(25,26)$. In this study, the nonuniform type of lung injury induced by repeated lung lavage might have contributed to the inhomogenous distribution of SP$C$, but it is possible that a part of the instilled surfactant had been cleared from the lung.

Clearance of surfactant from the lung takes place via the airways, by phagocytosis, enzymatic degradation within the alveolus, and transport by lymphatic ducts, but the major pathway probably is uptake by the type II alveolar cells, with subsequent reutilization (27). Uptake of surfactant phospholipids by alveolar cells was demonstrated for endotracheally administered tracer amounts of surfactant $(4,28-31)$ and recently for treatment doses of surfactant $(8,32)$. Bartussio et al. (33) demonstrated in 3-d-old rabbits that SP-C is taken up by the lung tissue similarly to phospholipids (33). These authors showed that the uptake of $\mathrm{SP}-\mathrm{C}$ is a rapid process.

If uptake of SP-C along with the phospholipids occurred also in our animals, this might explain the small amount of porcine surfactant polypeptide that we could localize $4 \frac{1}{2} \mathrm{~h}$ after instillation. As we stated above, there was sufficient alveolar surfactant during the spontaneous breathing, after weaning from the artificial ventilation, and it was possible that after uptake of the instilled porcine surfactant the phospholipids were resecreted into the alveolar space in a way similar to endogenous surfactant $(29,30)$. If this was true, then the porcine SP-C was not resecreted 
along with the phospholipids and therefore metabolized via another still unknown pathway.

Acknowledgment. The authors thank A. Heikamp for his excellent technical assistance during the experiments.

\section{REFERENCES}

1. Fujiwara T, Maeta H, Chida S, Morita T, Watabe Y, Abe T 1980 Artificial surfactant therapy in hyaline membrane disease. Lancet 1:55-59

2. Ikegami M, Jobe A, Jacobs H, Lam R 1984 A protein from airways of premature lambs that inhibits surfactant function. J Appl Physiol 57:11341142

3. Robertson B, Enhörning G 1974 The alveolar lining of the premature newborn rabbit after pharyngeal deposition of surfactant. Lab Invest 31(1):54-59

4. Geiger K, Gallagher ML, Hedley-Whyte J 1975 Cellular distribution and clearance of aerosolized dipalmitoyl lecithin. J Appl Physiol 39(5):759-766

5. Obladen M, Brendlein F, Krempien B 1979 Surfactant substitution. Eur J Pediatr 131:219-228

6. Jobe A, Ikegami M, Jacobs H, Jones S 1984 Surfactant and pulmonary blood flow distributions following treatment of premature lambs with natural surfactant. J Clin Invest 73:848-856

7. Ferrara TB, Hoekstra RE, Johnson P, Vernier RL 1987 Localization of surfactant in neonatal lung after exogenous administration. J Pediatr 111(3):463-466

8. Bambang Oetomo S, Reijngoud D-J, Ennema JJ, Okken A, Wildevuur ChRH 1988 Surfactant replacement therapy in surfactant deficient rabbits: early effects, lung function and biochemical aspects. Lung 166:65-73

9. Noack G, Berggren P, Curstedt T, Grossmann G, Herin P, Mortensson W, Nilsson R, Robertson B 1987 Severe neonatal respiratory distress syndrome treated with the isolated fraction of natural surfactant. Acta Paediatr Scand 76:697-705

10. Adams FH, Tower B, Osher A, Ikegami M, Fujiwara T, Nozaki M 1978 Effects of tracheal instillation of natural surfactant in premature lambs. Pediatr Res 12:841-849

11. Gruenwald P 1962 A numerical index of the stability of lung expansion. J Appl Physiol 18:645-667

12. Clements JA, Hustead F, Johnson RP, Gribetz J 1961 Pulmonary surface tension and alveolar stability. J Appl Physiol 16:444-450

13. Kennett RH 1980 Fusion protocols, fusion by centrifugation of cells suspended in polyethylene glycol. In: Kennett RH, McKearn RJ (eds) Monoclonal Antibodies. Plenum Press, New York, pp 365-367

14. De Ley L, Poppema S, Klein Nulend J, Ter Haar JG, Schwander E, The TH $1984 \mathrm{Immunoperoxidase} \mathrm{staining} \mathrm{on} \mathrm{frozen} \mathrm{tissue} \mathrm{sections} \mathrm{as} \mathrm{a} \mathrm{first} \mathrm{screening}$ assay in the preparation of monoclonal antibodies directed against small cel carcinoma of the lung. Eur J Cancer Clin Oncol 20(1):123-128

15. Curstedt T, Jörnvall H, Robertson B, Bergman T, Berggren P 1987 Two hydrophobic low-molecular-mass protein fractions of pulmonary surfactant. Characterization and biophysical activity. Eur J Biochem 168:255-262

16. Curstedt T, Johansson J, Barros-Söderling J, Robertson B, Nilsson G, Westberg
M, Jörnvall H 1988 Low-molecular-mass surfactant protein type 1. The primary structure of a hydrophobic $8-\mathrm{kDa}$ polypeptide with eight half-cystine residues. Eur J Biochem 172:521-525

17. Curstedt T, Johansson J, Persson P, Robertson B, Löwenadler B, Jörnvall H 1990 Hydrophobic surfactant-associated polypeptides: SP-C is a lipopeptide with two palmitoylated cysteine residues, whereas SP-B lacks covalently linked fatty acyl groups. Proc Natl Acad Sci USA 87:2985-2989

18. Weibel ER 1979 Stereological Methods, Vol 1. Academic Press, London, pp $120-121$

19. Anderson JM 1982 Histometry. In: Bancroft JD, Stevens A (eds) Theory and Practice of Histological Technique. Churchill Livingstone, London, pp 548563

20. Claypool WD, Wang DL, Chander A, Fisher AB 1984 "Hydrophobic" surfactant apoproteins and augmentation of phospholipid recycling. Exp Lung Res $6: 215-222$

21. Sueishi K, Tanaka K, Oda T 1977 Immunoultrastructural study of surfactant system. Lab Invest 37(2):136-142

22. Katyal SL, Singh G 1979 An immunologic study of the apoproteins of rat lung surfactant. Lab Invest 40(5):562-567

23. Walker SR, Williams MC, Benson B 1986 Immunocytochemical localization of the major surfactant apoproteins in type II cells, Clara cells and alveola macrophages of rat lung. J Histochem Cytochem 34(9):1137-1148

24. Walther FJ, Kuipers IM, Gidding CEM, Willebrand D, Buchholtz RTF, Bevers EM 1987 A comparison of high-frequency oscillation superimposed onto backup mechanical ventilation and conventional ventilation on the distribution of exogenous surfactant in premature lambs. Pediatr Res 22:725-729

25. Bambang Oetomo S, Lewis J, Ikegami M, Jobe A 1990 Surfactant treatments alter endogenous surfactant metabolism in rabbit lungs. J Appl Physiol 68:1590-1596

26. Gilliard N, Richman PM, Merritt TA, Spragg RG 1990 Effect of volume and dose on the pulmonary distribution of exogenous surfactant administered to normal rabbits or to rabbits with oleic acid lung injury. Am Rev Respir Dis 141:743-747

27. Jobe AH, Jacobs HC 1984 Catabolism of pulmonary surfactant. In: Robertson B, van Golde LMG, Batenburg JJ (eds) Pulmonary Surfactant. Elsevier, Amsterdam, pp 271-292

28. Hallman M, Epstein BL, Gluck L 1981 Analysis of labeling and clearance of lung surfactant phospholipids in rabbit. J Clin Invest 68:742-751

29. Jacobs H, Jobe A, Ikegami M, Conaway D 1983 The significance of reutilization of surfactant phosphatidylcholine. J Biol Chem 258(7):4159-4165

30. Jacobs H, Ikegami M, Jobe A, Berry DD, Jones S 1985 Reutilization of surfactant phosphatidylcholine in adult rabbits. Biochim Biophys Acta 837:77-84

31. Wright JR, Wagner RE, Hamilton RL, Huang M, Clements JA 1986 Uptake of lung surfactant subfractions into lamellar bodies of adult rabbit lungs. $J$ Appl Physiol 60:(3):817-825

32. Pettenazzo A, Jobe A, Ikegami M, Seidner S 1988 Clearance of treatment doses of surfactant. Biol Neonate 53:23-31

33. Bartussio A, Benevento M, Pettenazzo A, Bruni R, Santucci A, Dalzoppo D, Barcaglioni P, Crepaldi G 1989 The life cycle of a low-molecular-weight protein of surfactant (SP-C) in 3 day old rabbits. Biochim Biophys Acta 1006:19-25 